\title{
COLOR DEGRADATION KINETICS OF REHYDRATED 'BORLOTTO' BEANS STORED IN DIFFERENT GAS ATMOSPHERES AS MEASURED BY IMAGE ANALYSIS
}

\author{
Maria Luisa Amodio, Rosaria Cornacchia, Fedele Colantuono, Giancarlo Colelli
}

\section{Introduction}

Consumer demand of fresh and/or minimally processed ready-to-use vegetables is increasing driven by the lack of time for meal preparation and by the awareness of their nutritional value. Ready-to-cook soups made of fresh legume seeds and vegetables, may represent a suitable response to the basics of minimally processed foods market. The introduction of legume seeds in a fresh vegetable mix could be difficult to achieve, since a longer preparation/cooking time would be required due to their dried state. For this reason, legume seeds would benefit from previous re-hydration before mixing with other vegetables, even though this practice will make the final product more perishable in terms of sensorial and microbial quality. Low temperature and modified atmosphere within the package (MAP) may be used to prevent spoilage deterioration and quality loss [Watada 1996]. Gas composition with $2-5 \% \mathrm{O}_{2}$, at the recommended storage temperature, reduced the respiration rate of bean seeds [Saltveit 1997]. Gas compositions with 3-10\% $\mathrm{CO}_{2}$ reduced the discoloration phenomena of damaged seeds [Trail 1992], whilst gas compositions with higher $\mathrm{CO}_{2}$ concentrations [20-30\%] can be used only for short storage periods, otherwise off odors will be released [Costa 1994]. For ready-tocook vegetable soups, gas compositions at equilibrium with low $\mathrm{O}_{2}$ [3 \%] and high $\mathrm{CO}_{2}$ [20\%], resulted effective in reducing the 'Borlotto' beans' metabolic reactions and preserving their appearance and texture [Amodio 2006], even though for this kind of product it is difficult to quantify the color changes, due to the red areas on the seed husk that influence the measurement with traditional colorimetric systems. Colorimetric instruments in fact can operate only on flat and

Paper received 30.06.2011; accepted 19.09.2011

Dipartimento di Scienze delle Produzioni e dell'Innovazione nei sistemi agro-alimentari Mediterranei, Università degli Studi di Foggia, Via Napoli 25, Foggia. Corresponding author: m.amodio@unifg.it Tel. 0039.0881589105, fax 0039.0881589244 homogeneous surfaces, and in limited observation points, giving a measure that is not representative of the whole product, if the color is not uniform. The CIE L*a*b* color scale is the most used scale for color references, based on $\mathrm{L}^{*}, \mathrm{a}^{*}$, and $\mathrm{b}^{*}$ parameters and their derivative measures [Rossell 2006]. Among the other color spaces, HSV [Hue, saturation, value] is one of the most used, and it corresponds to the concepts of tint, amount of color and brightness, respectively [Hanbury 2002].

In alternative for cut-products where color is hard to determine, browning intensity and a fresh appearance may be evaluated using sensorial rating scales in order to evaluate general appearance and differences among treatment effects on fresh-cut produce as for peaches and nectarines [Gorny 1998, 1999; Aguayo 2006], vegetable mix [Amodio 2006] or mint leaves [Kenigsbuch 2007]. Kader and Cantwell [2004] put together experimental works on appearance evaluation rating scales and color charts for both whole and fresh-cut produce.

Image analysis techniques may represent a possible way to measure external features of fruits and vegetable as size [Blasco 2003], shape [Costa 2011] and color [Leon 2006]. These techniques can in fact isolate a region of interest within an image, by the operation of image partition [Gunasekaran 1996] which can be further processed in order to calculate the desired parameters. Image partition performed by means of an algorithm, allowed to evaluate color and browning incidence of basil leaves [Peri 2005] and artichokes [Amodio 2011], muscle color and marbling features on beef [Jackman 2009; Chen 2010], color changes and translucency development of tomato slices during storage at different temperatures [Lana 2006], or to model quality changes on whole mushrooms [Aguirre 2009], and fresh endives packaged in different atmospheres [Charles 2008].

To study the color changes over time, and more in general the visual appearance of the products, some kinetic models can be applied; for fresh-cut and minimally processed products, these parameters often follow a kinetic of zero or first order [Saguy 1980; Taoukis 1977; Piagentini 2005]. 
The present work was carried out in order to pursue the following objectives: 1) to design an algorithm to measure color of rehydrated 'Borlotto' beans; 2) to study the color degradation kinetics over time; 3) to evaluate the gas composition effect on chromatic changes and appearance of the seeds during storage at $5^{\circ} \mathrm{C}$.

\section{Materials and methods}

\subsection{Experimental design}

Dry 'Borlotto' bean seeds [Phaseolus vulgaris L.] were divided in three replicates, of $1 \mathrm{~kg}$ each, and rehydrated in water for 14 hours. After this time the rehydrated seeds of each replicate were drained for a few minutes, weighed and divided in 12 groups [4 treatments x 3 storage samplings] of about $140 \mathrm{~g}$. Each sample was placed in a plastic tray and groups of three trays were closed in 10-liter PVC containers with inlet and outlet tubes. The inlet tubes were connected to a gas mixer system for the gas distribution into the containers and all containers were cold stored at $5{ }^{\circ} \mathrm{C}$.

The gas compositions used were the following:

- $10 \% \mathrm{CO}_{2}$ in air;

$-3 \% \mathrm{O}_{2}$ in nitrogen;

- $10 \% \mathrm{CO}_{2}+3 \% \mathrm{O}_{2}$ in nitrogen;

- air, as control.

\subsection{Quality determination and image analysis techniques}

Initially, and after 5,10 and 15 days the following attributes were evaluated on 30 seeds from each replicate:

- appearance score, evaluated by 6 trained people using an anchored photographic scale as reference with scores from 5 to 1 ( $5=$ excellent; $4=$ good; 3 =fair; limit of marketability; $2=$ poor; limit of edibility; $1=$ =ery bad; not edible product) [Amodio 2006];

- color, by image analysis techniques. The images were acquired with a scanner 'hp OfficeJet G95' (Hewlett Packard, U.S.A.) and saved on the support PC hard disk, using a black background in the RGB (24 bit) mode. These images were then processed and analyzed by means of a codified algorithm in MATLAB 7.1 (MathWorks Inc., U.S.A.). A white sheet of paper was acquired at the beginning of each set of measures in order to check the stability of the acquisition system. The system was developed through different steps that are synthesized in Figure 1:

1- opening of one single image from a series of images analyzed in sequence;

2- conversion of the RGB image into the HSV (HueSaturation-Value) color space using the function included in the MATLAB image processing tool- box (MathWorks 2003) and separation of the H, S, $\mathrm{V}$ image components;

3- contrast enhancement, achieved generating a greyscale image obtained by adding the $\mathrm{S}$ and $\mathrm{V}$ component images $(\mathrm{S}+\mathrm{V})$;

4- $\mathrm{S}+\mathrm{V}$ image thresholding for background/foreground separation by using the Otsu method [Otsu 1979] followed by a flood filling operation [Soille 1999], obtaining a binary mask (bw) image, where ' 0 ' (black) is the background and ' 1 ' (white) the interest region representing the seeds;

5- R, G, and B image component extraction from the RGB image;

6- thresholding of the $\mathrm{G}$ image component within the interest region of the mask1 obtaining a second binary image, namely mask 2 , where ' 0 ' (black) are the red stripes and ' 1 ' the lighter pixels, i.e. the seed ground color;

7- generating a bw3 image complementary to the bw2, where ' 1 ' are the pixel of the red stripes and ' 0 ' the seed ground color;

8- conversion of the original RGB image in the $\mathrm{L}^{*} \mathrm{a} \mathrm{b}^{*}$ color space using the 'srgb2lab' function included in the MATLAB image processing toolbox;

9- calculation of the color parameters $\mathrm{L}^{*}, \mathrm{a}^{*}$ and $\mathrm{b}^{*}$ for the pixels with value 1 in the image bw 2 and bw3, the seed ground color and the red stripes, respectively;

10- results transcription on an excel file;

11- process reiteration until the last image of the sequence adding a row in the excel file for each image;

In addition, from the $\mathrm{L}^{*} \mathrm{a} * \mathrm{~b} *$ parameters, the Hue angle and Chromaticity parameters were calculated as follows:

$$
\begin{aligned}
& \text { Hue Angle }=\operatorname{arctg} \frac{b^{*}}{a^{*}} \\
& \text { chromaticity }=\sqrt{a^{* 2}+b^{* 2}} .
\end{aligned}
$$

\subsection{Kinetic parameters and linear regression}

To model color and general appearance changes over time the following equation was applied:

$$
\pm \frac{d[Q]}{d t}=k[Q]^{n}
$$

where $[Q]=$ quality attributes, $\mathrm{n}=$ order of reaction, $\mathrm{k}=$ kinetic rate constant $\left(\right.$ day $\left.^{-1}\right)$ and $t=$ time (day). The slope of the plot between quality attribute and time is the kinetic rate constant $(\mathrm{k})$, normally following a zero or a first order kinetic [Labuza 1982]. This constant was determined comparing the coefficients of determination $\left(R^{2}\right)$, the $p$ values and the residuals for the estimated value of the intercept in the case of reaction order 0 and 1 .

In order to find a correlation between color changes of 'Borlotto' beans and appearance score, a 
linear regression between $\mathrm{a}^{*}$ and Hue angle of the beans' ground color versus score was run; coefficients of correlation and $\mathrm{p}$ values are reported.

\subsection{Statistical analysis}

A split-plot statistical design was applied to analyze the variance of all data with the software SAS (Sas Institute, Inc., V 8.2, Cary, NC, USA), with gas treatment as first factor and time as second factor. For time and interaction treatment $\mathrm{X}$ time the most conservative method of degree of freedom estimation was used. For each sampling a one way ANOVA for the gas treatment was applied. Mean values were separated using the Tukey test at a confidence level of $95 \%$ $(\mathrm{P}=0.05)$.

\section{Risults and discussion}

The defined algorithm allowed the partitioning of a total of 39 pictures in a few minutes, exporting the color data already in a file excel immediately available for further processing. Color parameters of both red stripes and seed ground color were monitored during 15 days of storage at $5^{\circ} \mathrm{C}$.

The gas atmospheres applied during seed storage showed a significant effect on the appearance score, $a^{*}$ and Hue angle of seed ground color, while the storage time had always a significant effect on all parameters. No interaction between the gas treatment and the storage time was observed, with the exception of $\mathrm{L}^{*}$ value.

The effects of each storage atmosphere and of each storage time are shown in Tables 1 and 2, respectively.

Seed appearance score was assigned based on color, dehydration and husk separation level; seeds stored with the $3 \% \mathrm{O}_{2}$ plus $10 \% \mathrm{CO}_{2}$ received the highest score according to these criteria (Table 1).

A gradual reduction of the appearance score over time was observed, decreasing from 4.5 to 2.8 after 15 days of storage (Tab. 2).

The shelf-life at $5{ }^{\circ} \mathrm{C}$ for this kind of product was therefore approximately 10 days, regardless of the at-

\begin{tabular}{|c|c|c|c|c|c|c|c|c|}
\hline \multirow[b]{2}{*}{ Scone } & & \multicolumn{2}{|c|}{ CTRL } & \multicolumn{2}{|l|}{$3 \% \mathrm{O}_{2}$} & \multicolumn{2}{|c|}{$10 \% \mathrm{CO}_{2}$} & $3 \% \mathrm{O}_{2}+10 \% \mathrm{CO}_{2}$ \\
\hline & & 3.5 & b & 3.5 & b & 3,4 & b & $3.7 \mathrm{a}$ \\
\hline & Growend color & & & & & & & \\
\hline $\mathrm{L}^{*}$ & & 64.9 & ns & 65.1 & ns & 65.0 & ns & $64.9 \mathrm{~ns}$ \\
\hline$a^{*}$ & & 10.0 & a & 9.7 & b & 10.0 & a & $10.0 \mathrm{a}$ \\
\hline$b^{*}$ & & 18.6 & ns & 18.6 & ns & 18.8 & ns & $185 \mathrm{~ns}$ \\
\hline Hue angle $\left({ }^{\circ}\right)$ & & 1.08 & a & 1.09 & a & 1.08 & a & $1.07 \mathrm{~b}$ \\
\hline Chromaticity & & 21.1 & ns & 21.0 & ns & 21.3 & ns & $21.1 \mathrm{~ns}$ \\
\hline & Redsrripes & & & & & & & \\
\hline $\mathrm{L}^{*}$ & & 42.1 & ns & 42.3 & ns & 42.1 & ns & $42.1 \mathrm{~ns}$ \\
\hline$a^{*}$ & & 14,0 & ns & 13.8 & ns & 13,9 & ns & $13.6 \mathrm{~ns}$ \\
\hline$b^{*}$ & & 14.9 & ns & 14.7 & ns & 15.0 & ns & $14.7 \mathrm{~ns}$ \\
\hline Hue angle ( & & 0.82 & ns & 0.82 & ns & 0.83 & ns & $0.83 \mathrm{~ns}$ \\
\hline Chromaticity & & 20.4 & ns & 20.2 & ns & 20.4 & ns & $20.1 \mathrm{~ns}$ \\
\hline
\end{tabular}

TABLE 1 - Effect of gas composition on appearance score and color parameters ( $L^{*}, a^{*}$, and $\left.b^{*}\right)$ of rehydrated 'Borlotto' beans stored for 15 days at $5^{\circ} \mathrm{C}(\mathrm{N}=9)$. Different letters on each row indicate a significant difference among treatments $(\mathrm{P}=0.5)$.

\begin{tabular}{|c|c|c|c|c|c|c|c|c|}
\hline & \multicolumn{2}{|l|}{0} & \multicolumn{2}{|l|}{5} & \multicolumn{2}{|c|}{10} & \multicolumn{2}{|c|}{15} \\
\hline Appearance Score & 4.5 & a & 3.4 & $a b$ & 3.5 & $a b$ & 2.8 & b \\
\hline \multicolumn{9}{|c|}{ Background color } \\
\hline $\mathrm{L}^{*}$ & 64.1 & bc & 66.0 & a & 65.6 & $a b$ & 64.3 & c \\
\hline$a^{*}$ & 10.8 & a & 9.7 & $b$ & 9.6 & b & 9.6 & b \\
\hline$b^{*}$ & 18.2 & ns & 18.7 & ns & 18.7 & ns & 18.9 & ns \\
\hline Hue angle $\left({ }^{\circ}\right)$ & 1.04 & b & 1.09 & a & 1.10 & a & 1.10 & a \\
\hline Chromaticity & 21.2 & ns & 21.1 & ns & 21.2 & ns & 21.2 & ns \\
\hline \multicolumn{9}{|c|}{ Red area color } \\
\hline 1.* & 41.6 & ns & 42,8 & ns & 42.2 & ns & 42.1 & ns \\
\hline$a^{*}$ & 15.8 & $\mathbf{a}$ & 13.7 & b & 13.0 & bc & 12.5 & c \\
\hline$b^{*}$ & 15.2 & ns & 14.4 & ns & 14.5 & ns & 15.1 & ns \\
\hline Hue angle $\left({ }^{\circ}\right)$ & 0.76 & b & 0.81 & b & 0.83 & $a b$ & 0.88 & a \\
\hline Chromaticity & 22.0 & ns & 19.9 & as & 19.5 & ns & 19.7 & ns \\
\hline
\end{tabular}

TABLE 2 - Effect of time of storage on appearance score and color parameters ( $L^{*}, a^{*}$, and $\left.b^{*}\right)$ of rehydrated 'Borlotto' beans stored for 15 days at $5^{\circ} \mathrm{C}(\mathrm{N}=5)$. Different letters on each row indicate a significant difference among treatments $(\mathrm{P}=0.5)$. 

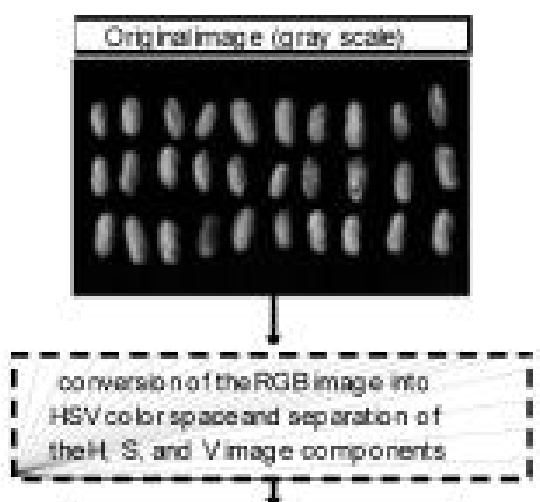

constrasted image $5+\mathrm{V}$
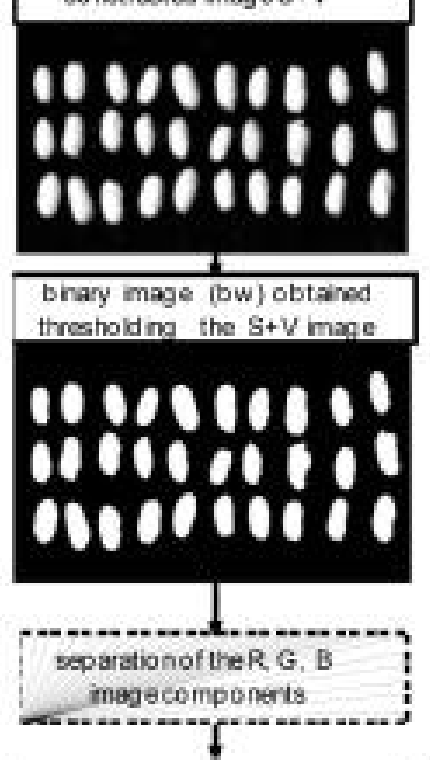

Birsary imsge (bure) obtained threstolding the G inage

1000010 : 0

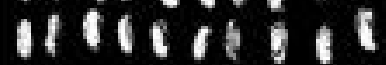
118.011808

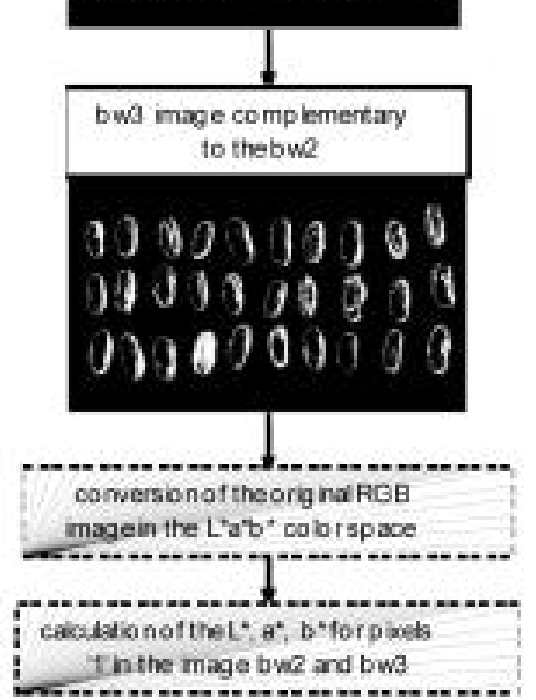

Fig. 1 - Workflow of the image analysis operations (dot lines) and products (image description in solid lines) generated in Matlab 7.1 to partition the RGB images into the interest regions. mospheres applied, since after 15 days all treatments received a score below 3 , considered as the limit of marketability. This shelf-life was longer than that reported by Amodio et al. [2006] for 'Borlotto' beans mixed with other vegetables and stored with $20 \%$ $\mathrm{CO}_{2}$, either in air or in low oxygen, which at 10 days of storage presented an appearance score lower than the marketability limit. It could be that in that study the ethylene production by the other species included in the mix, as tomato, reduced the seed shelf-life [Saltveit 1999].

In Figure 2 the changes over time of $\mathrm{a}^{*}$ and Hue angle of seed ground color are shown. It can be ob-
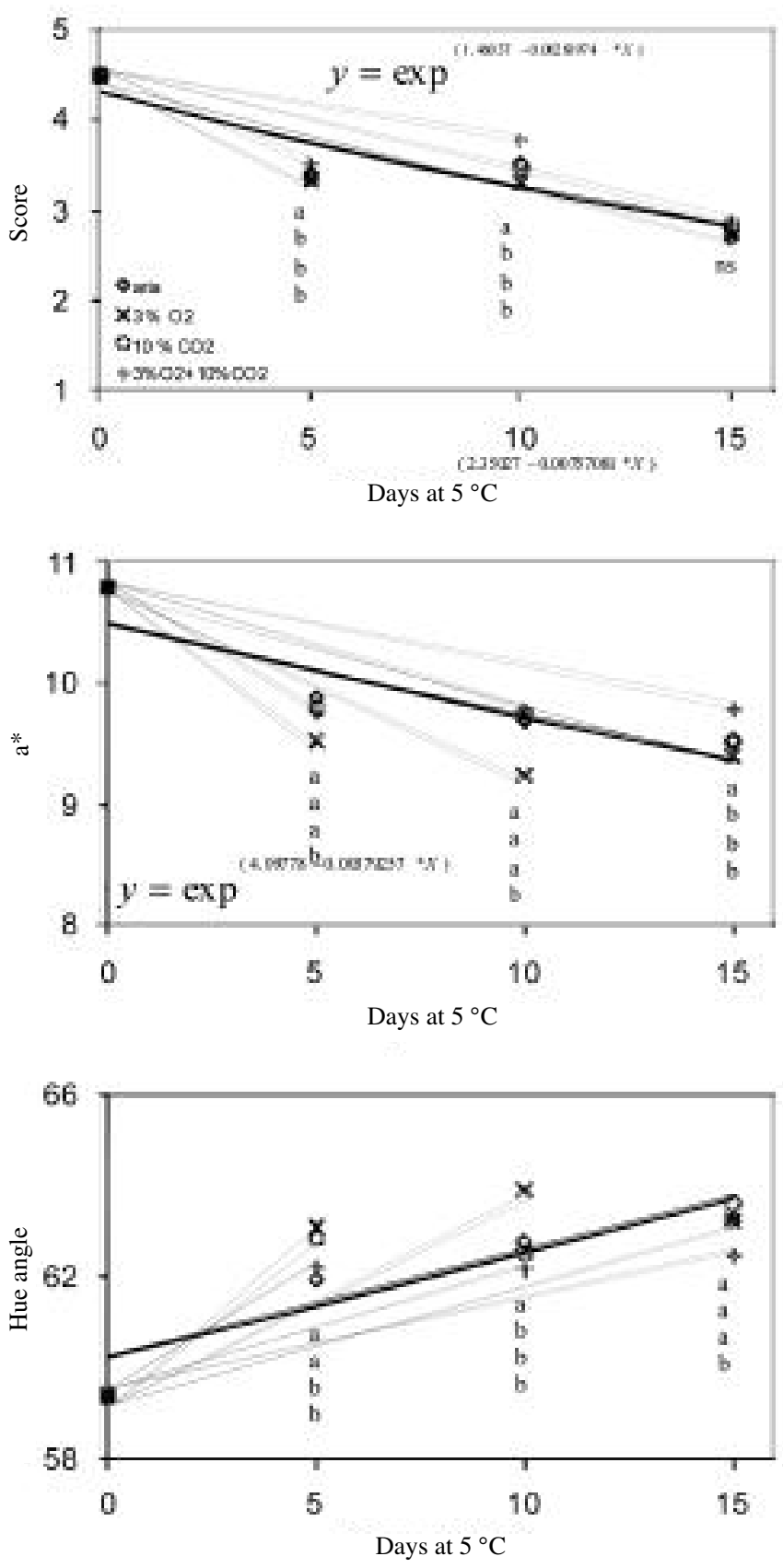

Fig. 2 - Appearance score, $a^{*}$ and Hue angle changes over time of the ground color of 'Borlotto' beans at the indicated atmosphere conditions. The solid line shows the evolution of each parameter using the fitted model shown in the relative equation. 


\begin{tabular}{lcccc}
\hline & Order & Kinetic rate constant (day ${ }^{-1}$ ) & $\mathrm{R}^{2}$ & $\mathrm{P}$ \\
\hline Appearance score & 0 & -0.100 & 0.818 & 0.0000 \\
& 1 & -0.028 & 0.829 & 0.0000 \\
$\mathrm{a}^{*}$ (ground color) & 0 & -0.077 & 0.644 & 0.0001 \\
& 1 & -0.004 & 0.677 & 0.0001 \\
Hue angle (ground color) & 0 & 0.235 & 0.677 & 0.0001 \\
& 1 & 0.004 & 0.677 & 0.0001 \\
Hue angle (red stripes) & 0 & 0.422 & 0.904 & 0.0000 \\
\hline
\end{tabular}

TABLE 3 - Kinetic rates, coefficient of determination $\left(\mathrm{R}^{2}\right)$ and $\mathrm{p}$ values for 0 and 1 order kinetics of appearance score and color parameters.

served that seeds stored with $3 \% \mathrm{O}_{2}+10 \% \mathrm{CO}_{2}$, which received the highest appearance score, showed the lowest $\mathrm{a}^{*}$ and Hue angle variation of the ground color as well. Up to 10 days of storage the appearance score of the seeds stored in $3 \% \mathrm{O}_{2}+10 \% \mathrm{CO}_{2}$ was significantly higher than that of seeds stored in the others atmosphere compositions (Fig. 2).

On the other hand, seeds stored with low oxygen atmosphere which showed generally the lowest appearance score (as absolute value) presented also the highest reduction of the $\mathrm{a}^{*}$ value and the highest increase in Hue angle.

As for the color of the red stripes the atmosphere with $3 \% \mathrm{O}_{2}$ induced the lowest changes in Hue angle values as shown in Figure 3.

The coefficients of determination $\left(\mathrm{R}^{2}\right)$ and the significance level of slope values obtained from the equation (3) for values $n=0$ and $n=1$ were compared in order to determine which kinetic best fit the quality changes over time.

First order was the apparent order of the quality change reactions (Tab. 3), even though in some cases only a slight improvement of the $\mathrm{R}^{2}$ was observed. These results were also supported by the plots of residuals versus predicted values (not shown) indicating that the distribution around zero was more random for the first order model. These results confirmed

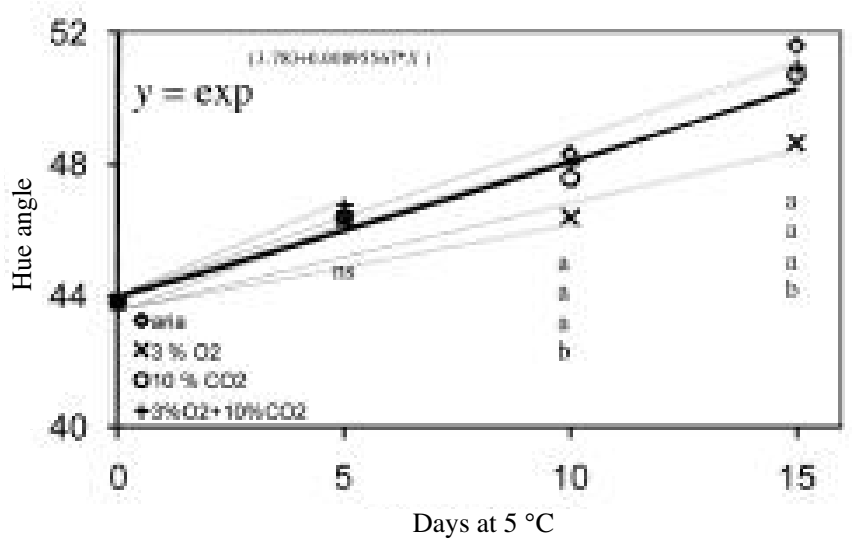

Fig. 3 - Hue angle changes over time of the red stripes of 'Borlotto' beans at the indicated atmosphere conditions. The solid line shows the evolution of Hue angle using the fitted model shown in the equation. what was found by other authors [Vankerschaver 1996; Piagentini 2004, 2005] which observed that first order was the most adequate kinetic model for fitting sensory characteristic changes in minimally processed vegetables. The solid line in the Figure 2 shows the evolution of each predicted attribute using the fitted models described by the equation reported in each graph.

In addition in Table 3 it is possible to observe that the constants of kinetics obtained for degree 0 are higher than those obtained for degree 1, with differences of two decimal digits, but the direct comparison is not meaningful due to the difference between the two models. The model with order 0 involves a constant variation over time of the considered parameters with a linear equation like $\mathrm{Q}=\mathrm{Q}_{0} \pm \mathrm{k} * \mathrm{t}$, where $\mathrm{t}$ is the number of days in storage, $\mathrm{Q}_{0}$ is the initial value that will change over time by a quantity kt; a model with order 1 is described through an exponential equation like $\mathrm{Q}=\mathrm{Q}_{0} \pm \mathrm{k} * \mathrm{t}$, where the quantity $\mathrm{kt}$ will change according to the elapsed number of storage days and will influence the final value $\mathrm{Q}$ that will be multiplied or divided by the quantity $\exp ^{k t}$. The $\mathrm{k}$ value related to the first order kinetic is in line with references indicated by other authors on asparagus [Sothornvit 2009] and fresh-cut cicory appearance [Piagentini 2005] within a temperature range of $0-5{ }^{\circ} \mathrm{C}$. On the other hand it results lower than values for fresh-cut Iceberg and Romain lettuce [Piagentini 2005], that at $4.3{ }^{\circ} \mathrm{C}$ showed a constant kinetic, circa 0.1 day $^{-1}$, probably due to the high perishability (browning and dehydration) of these products.

Since the results suggested a possible correlation between score and color changes of the ground color, a linear regression was performed. Results of this analysis are reported in Table 4 . Both $\mathrm{a}^{*}$ index and Hue angle showed a high coefficient of correlation

\begin{tabular}{lrcc}
\hline Color parameter & $\mathrm{R}$ & $\mathrm{R}^{2}$ & $\mathrm{P}$ \\
\hline $\mathrm{a}^{4}$ & 0.9021 & 0.8138 & 0.0001 \\
Hue Angle & -0.9139 & 0.8352 & 0.0001 \\
\hline
\end{tabular}

TABLE 4 - Coefficients of correlation (R) and determination $\left(\mathrm{R}^{2}\right)$, and $\mathrm{p}$ values of linear regression between color parameters ( $\mathrm{a}^{*}$ and Hue angle) and appearance score. 
with a $\mathrm{p}$ value $<0.0001$, explaining more than $80 \%$ of the total variance. For $\mathrm{a}^{*}$ the value $\mathrm{R}$ was 0.90 , while for Hue angle was -0.91 , indicating for the last parameter a negative correlation with the parameter score. In fact, while score and $a^{*}$ values, decreased over time, Hue angle increased. These results confirmed what previously reported by other Sothornvit and Kiatchanapaibul [2009] that found on asparagus a $68 \%$ of correlation between visual quality and Hue Angle during storage at different temperatures.

\section{Conclusions}

Results of this work allowed to evaluate color variation during storage of rehydrated 'Borlotto' bean seeds, which would be impossible to evaluate with traditional colorimetric systems, due to the high red area variability in the seeds. A new rapid approach for color data calculation and storing of this kind of product has been developed.

The change of seed ground color and appearance, evaluated through a sensorial scale, followed a first order kinetic. Among the treatments applied, the $3 \%$ $\mathrm{O}_{2}+10 \% \quad \mathrm{CO}_{2}$ atmosphere influenced positively the seeds' quality and appearance, reducing the husk discoloration up to 10 days storage. In general none of the tested treatments gave beneficial effects for the seeds' marketability during periods longer than 10 days. A positive regression between the sensorial evaluation and the $\mathrm{a}^{*}$ index retention was found, while the Hue angle ground color change resulted inversely related to the seeds' score. The results also indicated that the most determinant factor on 'Borlotto' beans' sensorial quality is related to the changes of seed ground color.

\section{References}

Aguayo E., Jansasithorn R., Kader, A.A., Combined effects of 1-methylcyclopropene, calcium chloride dip, and/or atmospheric modification on quality changes in freshcut strawberries. Postharvest Biology and Technology, 2006, 40, 269-278.

Aguirre L., Frias J.M, Barry-Ryan C., Grogan H., Modelling browning and brown spotting of mushrooms (Agaricus bisporus) stored in controlled environmental conditions using image analysis. Journal of Food Engineering, 2009, 91, 280-286.

Amodio M.L., Rinaldi R., Colelli G., Influence of atmosphere composition on quality attributes of ready-tocook fresh-cut vegetable soup. Acta Horticulturae (ISHS) 2006, 712, 677-684

Amodio M.L, Cabezas-Serrano A. B., Peri G., Colelli G., Post-cutting quality changes of fresh-cut artichokes treated with different anti-browning agents as evaluated by image analysis. Postharvest biology and technology, 2011, 213-220.

Blasco J., Aleixos N., Moltó E., Machine vision system for automatic quality grading of fruit. Biosystem Engineering, 2003, 85, 415-423.
Charles F., Guillaume C., Gontard N., Effect of passive and active modified atmosphere packaging on quality changes of fresh endives. Postharvest Biology and Technology, 2008, 48, 22-29.

Chen K., Suna X., Qin Ch., Tang X., Color grading of beef fat by using computer vision and support vector machine. Comput. Electron. Agric., 2010, 70, 27-32.

Costa M. A. C., Brecht J.K., Sargent S. A., Huber D. J., Tolerance of snap beans to elevated $\mathrm{CO}_{2}$ levels. Proc. Fla. State Hort. Soc., 1994, 107:271-273.

Costa C., Antonucci F., Pallottino F., Aguzzi J., Sun D.W., Menesatti P., Shape analysis of agricultural products: a review of recent research advances and potential application to computer vision. Food and Bioprocess Technology, 2011, 4, 673-692.

Gorny J.R., Hess-Pierce B., Kader, A.A., Effect of fruit ripeness and storage temperature on the deterioration rate of fresh-cut peach and nectarine slices. Hortscience, 1998, 33, 110-113.

Gorny J.R., Hess-Pierce B., Kader A.A., Quality changes in fresh-cut peach and nectarine slices as affected by cultivar, storage atmosphere and chemical treatments. Journal of food science, 1999, 64, 429-432.

Gunasekaran S., Computer vision technology for food quality assurance. Trends in Food Science and Technology, 1996, 7, 2, 245-255.

Hanbury A., The taming of the hue, saturation, and brightness color space. IN CVWW '02 Computer Vision Winter Workshop (WIdenauer H,Kropatsch WG, eds), 2002, Bad Aussee, pp. 234-243.

Jackman P., Da-Wen S., Allen P., Automatic segmentation of beef longissimus dorsi muscle and marbling by an adaptable algorithm. Meat Science 83,187-194.

Kader, A.A. and Cantwell, M., Produce Quality Rating Scales and Color Charts. Postharvest horticulture series $\mathrm{N}^{\circ} 23$, September 2004, revised May 2007. Postharvest Technology Research \& Information Center. University of California [Eds.], Davis CA-USA.

Kenigsbuch D., Chalupowicz D., Aharon Z., Maurer D., Aharoni N., The effect of $\mathrm{CO}_{2}$ and 1-methylcyclopropene on the regulation of postharvest senescence of mint, Mentha longifolia L." Postharvest Biology and Technology, 2007, 43, 165-173.

Labuza T.P., Open shelf life dating of foods. Westport, Conn.: Food and Nutrition Press, 1992.

Lana MM; Tijskens LMM; Kooten OV Modelling RGB colour aspects and translucency of fresh-cut tomatoes. Postharvest Biology ant Technology, 2006, 40, 15-25.

Leon K., Mery D.; Pedreschi F., Leon J., Color measurement in L*a*b* units from RGB digital images. Food Research International, 2006, 39, 1084-1091.

Peri G., Romaniello R., Amodio M.L., Colelli G., Tecniche di analisi di immagine come mezzo per la valutazione dell'imbrunimento di carciofi di IV gamma. Atti del Convegno Nazionale $\mathrm{III}^{\circ}, \mathrm{V}^{\circ} \mathrm{e} \mathrm{VI}^{\circ}$ Sezione A.I.I.A. "Tecnologie innovative nelle filiere: orticola, vitivinicola e olivicola-olearia", 2007.

Peri G., Romaniello R., Colelli G., Amodio M. L., Misurazione della qualità dei prodotti orticoli in foglia mediante analisi d'immagine. Atti del convegno A.I.I.A. 2005, Catania 27-30 Giugno, 241. [Measuring quality of leafy vegetables with image analysis techniques, Proceeding of A.I.I.A. conference 2005]. 
Piagentini A.M., Pirovani M.E., Güemes D.R., Cinética de deterioro de la calidad de repollo fresco cortado. Cien. Tecnol. Alimentaria, 2004, 4, 169-176.

Piagentini A.M., Mendez J.C., Guemes D.R., Pirovani M. E., Modelling changes of sensory attributes for individual and mixed fresh-cut leafy vegetables. Postharvest Biology ant Technology, 2005, 38, 202-212.

Saguy I., Karel M., Modeling of quality deterioration during food processing and storage. Food Technol.,1980, $34,78-85$.

Saltveit M.E., Physical and physiological changes in minimally processed fruits and vegetables. In F.A. TomàsBarberàn and R.J. Robins, eds. Phytochemistry of fruits and vegetables, Phytochem. Soc. Europe, Clarendon, Oxford, 1997, 205-220.

Saltveit M.E., Effect of ethylene on quality of fresh fruits and vegetables. Postharvest Biol. Technol., 1999, 15, 279-292.

Sothornvit R., Kiatchanapaibul P., Quality and shelf-life of washed fresh-cut asparagus in modified atmosphere packaging. LWT - Food Science and Technology, 2009, 42, 1484-1490.

Taoukis P.S., Labuza T.P., Saguy I., Kinetics of food deterioration and shelf-life prediction. In: Valentas K.J., Rotstein E., Singh R.P. (Eds), The handbook of food engineering practice. CRC Press, NY, USA, 1977, pp. 363405.

Trail M.A., Wahem I.A., Bizri J.N., Snap bean quality changed minimally when stored in low density polyolefin film package. Journal of Food Science, 1992, 57, 977-979.

Vankerschaver K., Willocx F., Smout C., Hendrickx M., Tobback P., Modeling and prediction of visual shelf life of minimally processed endive. J. Food Sci., 1996, 61, 1094-1098.
Watada A.E., Ko N.P., Minott D.A., Factors affecting quality of fresh-cut horticultural products. Postharvest Biology and Technology, 1996, 9, 115-125.

\section{SUMMARY}

Rehydrated legume seeds represent an important ingredient for ready-to-cook fresh soups packaged in a modified atmosphere. The aim of this work was to define an image analysis system for the evaluation of 'Borlotto' bean color changes during storage in different gas compositions. 'Borlotto' bean seeds were rehydrated in water for 12 hours and stored at $5{ }^{\circ} \mathrm{C}$ in controlled atmosphere using 4 different gas compositions: $3 \% \mathrm{O}_{2}, 10 \% \mathrm{CO}_{2}$ in air, $3 \% \mathrm{O}_{2}+10 \% \mathrm{CO}_{2}$, and air as control. An algorithm in Matlab was codified to measure color of the seed red stripes and ground color (L*, $\mathrm{a}^{*}, \mathrm{~b}^{*}$, Hue angle and Chromaticity). Sensorial analyses based on the hedonic scale (from $5=$ excellent to $1=$ very bad) of the seed appearance were also carried out. Seed color and appearance changes over time were monitored initially and after 5, 10 and 15 days of storage at $5{ }^{\circ} \mathrm{C}$. The obtained data were used to model the quality of degradation attributes over time, that were fit into first order kinetics.

A gas composition with $3 \% \mathrm{O}_{2}+10 \% \mathrm{CO}_{2}$ induced the least modification on the seed ground color, which received a highest appearance evaluation up to 10 days of storage, also showing that visual appearance changes were mostly affected by the variation of the seed ground color.

Keywords: appearance, Hue angle, computer vision, ready to use. 
